\title{
Solution to Stability Analysis in Stratified Liquid Film Flow- ing down an Inclined Heated Plate
}

\author{
Y. L. Cheng*, Y. Tian* \\ Department of Powcr Engineering, North China Electric Power University, Baoding, Hebei 071003, \\ China \\ Email: ylcheng001@163.com \& tian13755@sina.com.cn
}

\begin{abstract}
The stability analysis in a stratified liquid film flowing down an inclined heated plate is investigated by using small perturbation method. The boundary value problem of the stability differential equation on small perturbation for general density distribution is derived. Then, the boundary value problem is solved and the solution to the problem is obtained for a special case. The result for non-stratified is agrecment with the known one.
\end{abstract}

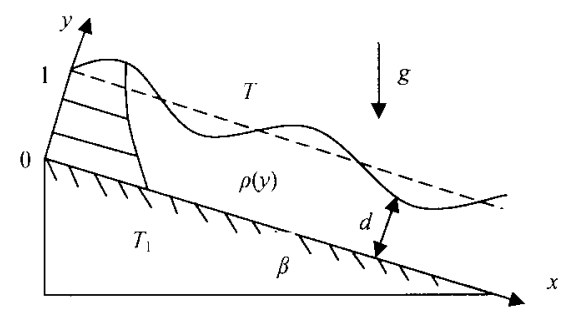

Figure: Stratified fluid film flowing down an inclines heated plate

\section{REFERENCES}

1. Benjamin, TB. Wave formulation in laminar flow down an inclined plane. J. Fluid. Mech, 1957;2:554-574.

2. Yih, CS. Stability of liquid flow down an inclined plane. Phys. Fluid, 1963;6:321-334.

3. HU J, HU GH. A review on thin films falling along an inclined plane. Advances in Mechanics, 2005;35(2):161-169.

4. Weinstein, S J., Kurz, M R. Long-wavclength instabilities in three-layer flow down an incline. Phys. Fluids A, 1991;3:2680-2687.

5. HU J., HU GH. Instability of liquid film flowing down a linearly heated plate. Progress in Natural Science, $2003 ; 13(8): 568-572$. 